\title{
Reducing barriers to accessing fistula repair: Implementation research in Katsina
}

\author{
Pooja Sripad \\ Population Council \\ Emmanuel Nwala \\ Population Council \\ Vandana Tripathi
}

Follow this and additional works at: https://knowledgecommons.popcouncil.org/departments_sbsr-rh

Part of the International Public Health Commons, Maternal and Child Health Commons, Obstetrics and Gynecology Commons, Social and Behavioral Sciences Commons, and the Women's Health Commons How does access to this work benefit you? Let us know!

\section{Recommended Citation}

Sripad, Pooja, Emmanuel Nwala, and Vandana Tripathi. 2018. "Reducing barriers to accessing fistula repair: Implementation research in Katsina," brief. Washington, DC: Population Council. 


\section{REDUCING BARRIERS TO ACCESSING FISTULA REPAIR: IMPLEMENTATION RESEARCH IN KATSINA}

\section{BACKGROUND}

Female genital fistula is preventable and surgically treatable, but women who lack access to quality healthcare often live with fistula for many years. For every 1,000 births, an estimated 2.11 women develop fistula in Nigeria ${ }^{1}$ and despite the establishment of internationally accredited national fistula centers (NOFIC) across the country, the majority of women live with unrepaired fistula.

Formative research conducted in 2015 highlighted barriers that impact access to fistula care services, including lack of knowledge about fistula among lower level providers, women, and their families; transportation and financial costs; fear and stigma; weak community and facility referral systems; and lack of counseling services for women and communities.

\section{IMPLEMENTATION RESEARCH}

Population Council, in collaboration with EngenderHealth and the Fistula Care Plus (FC+) project, conducted implementation research to understand whether a comprehensive information, screening, and referral intervention reduces transportation, communication, and financial barriers to accessing preventive care, detection, and treatment of fistula in Katsina State. Following a baseline assessment, a multi-pronged intervention utilizing a fistula mobile hotline, transport voucher, and mass media tools to increase community awareness was implemented. The 12-month intervention convened an initial training of 46 primary health care $(\mathrm{PHC})$ providers and 36 community agents to better identify and refer women with fistula. Fourteen PHC providers and 21 community agents received a refresher training following midline data collection, and an endline evaluation occurred following the intervention (Figure 1).

\section{FIGURE 1}

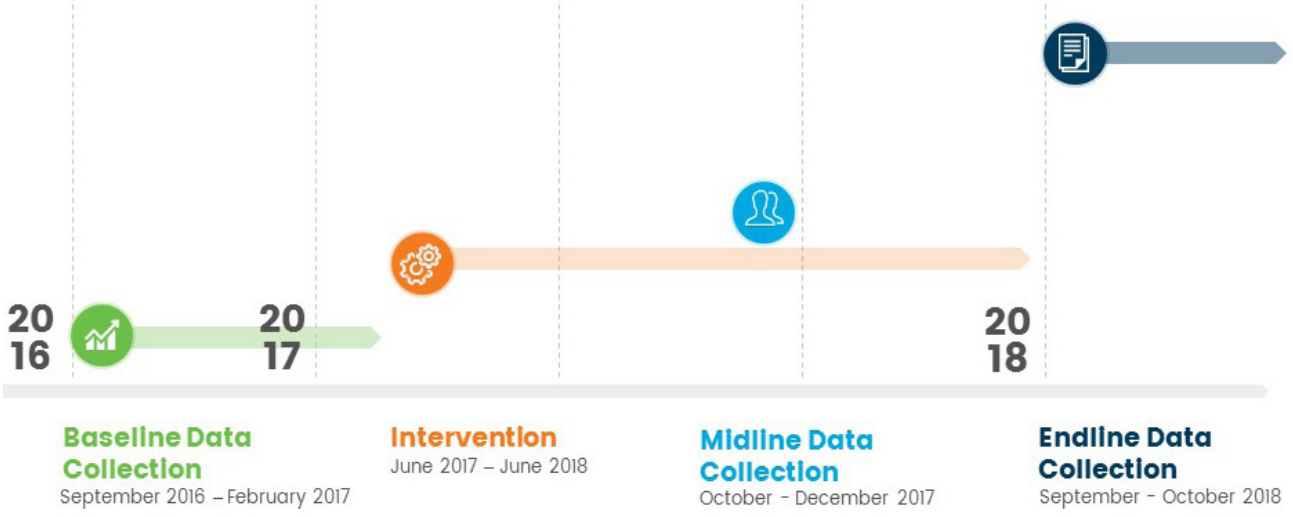

\section{Highlights}

- Implementation of a mobile hotline, community volunteers, job aids at primary health centers, and transport vouchers increased referrals and access to fistula repair services at specialized centers.

- More primary healthcare providers at endline recognize and refer fistula patients, though knowledge gaps and turnover remain.

- Fewer psychological, transportation, and financial barriers, and beliefs of supernatural causes of fistula were observed.

- The hotline and communityto-facility referrals improved access to fistula services for stigmatized populations.

- Health systems and external stakeholder support are essential for sustaining trends.

The Population Council conducts research and delivers solutions that improve lives around the world.

Big ideas supported by evidence:

It's our model for global change. popcouncil.org

(c) 2018 The Population Council, Inc. 


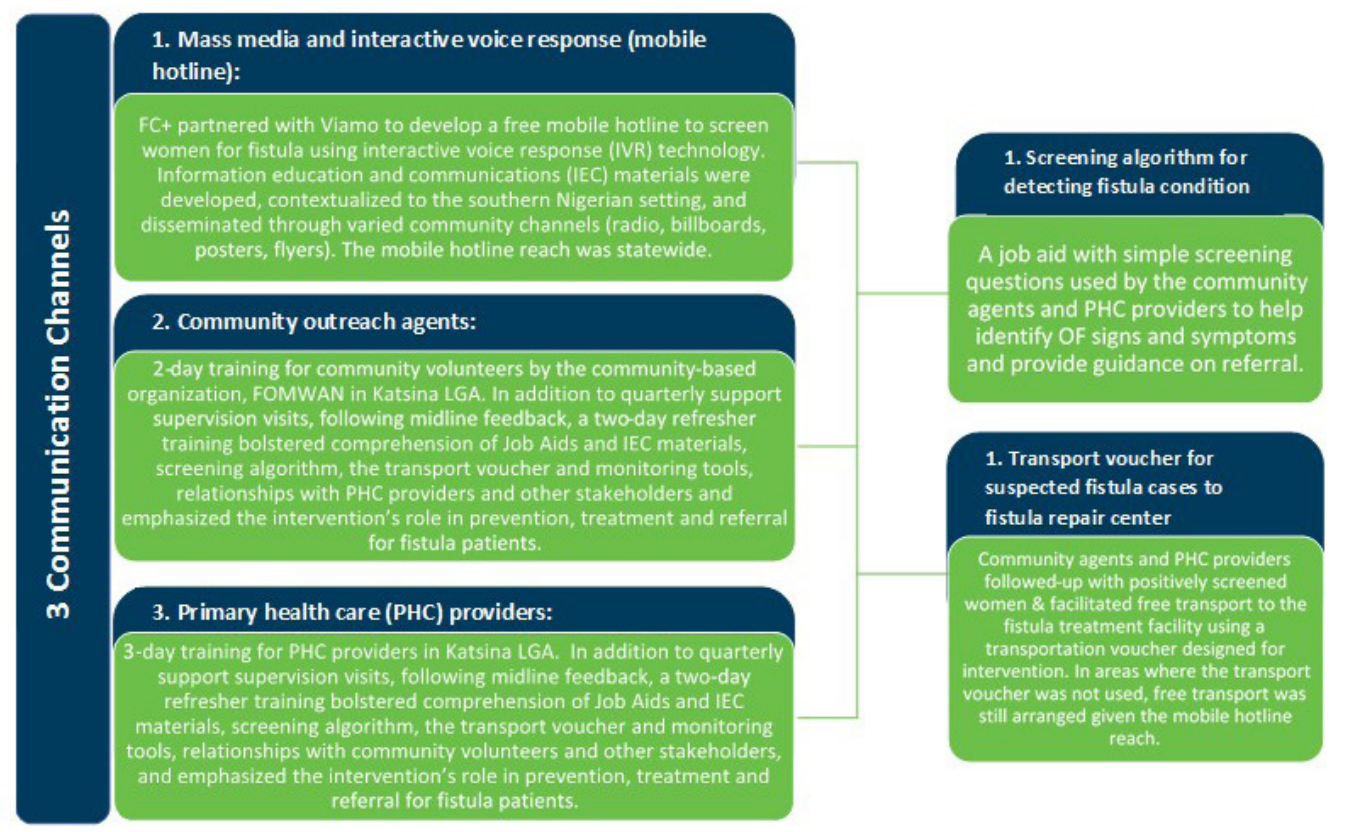

\section{Intervention}

The intervention, implemented by $\mathrm{FC}+$, followed a " 3 1-1" model that applied three communication channels for messaging, one screening algorithm for detection at the PHC, and one transport voucher to enable access to a hospital for diagnosis and repair.

\section{Methods and Data Sources}

Mixed methods were used to investigate:

(a) Intervention outcomes, includingfistula repair referrals, provider knowledge and practice, women's fistula status, barriers and enablers to care, and community awareness of fistula causes and care options (b) Challenges, successes, and sustainability implications for screening and referral at community and PHC levels using the hotline, job aides, and the transport voucher.

Data collection activities in Katsina (intervention) and Batsari (comparison) local government areas (LGA) at baseline, midline and endline are outlined in Table 1.

While the mobile hotline component of the intervention was accessible throughout Katsina State, the intervention LGA refers to the additional community volunteer and PHC provider trainings and the transport voucher implementation conducted in Katsina LGA.

\section{TABLE 1: DATA COLLECTION ACTIVITIES}

\begin{tabular}{|c|c|c|c|c|}
\hline Method & Purpose & Baseline & Midline & Endline \\
\hline Assessment of PHC facility & $\begin{array}{l}\text { Assessed health system capacity \& contextualized intervention } \\
\text { setting }\end{array}$ & 37 & $\mathrm{n} / \mathrm{a}$ & 31 \\
\hline Survey of PHC providers & $\begin{array}{l}\text { Assessed knowledge, attitudes and operational challenges around } \\
\text { intervention implementation }\end{array}$ & 88 & $\mathrm{n} / \mathrm{a}$ & 93 \\
\hline Survey of post-repair women & Explored fistula history, experience of barriers \& enablers & 81 & $\mathrm{n} / \mathrm{a}$ & 44 \\
\hline $\begin{array}{l}\text { Focus Group Discussion with } \\
\text { community men and women }\end{array}$ & $\begin{array}{l}\text { Explored barriers and enablers to accessing care and normative } \\
\text { attitudes toward fistula causes and consequences }\end{array}$ & 4 & $\mathrm{n} / \mathrm{a}$ & 8 \\
\hline $\begin{array}{l}\text { Program monitoring } \\
\text { statistics (from Viamo and } \\
\text { EngenderHealth) }\end{array}$ & $\begin{array}{l}\text { Assessed number of hotline callers, referrals, transport vouchers, } \\
\text { fistula center trips, and community-based follow up }\end{array}$ & & $\mathrm{n} / \mathrm{a}$ & $\mathrm{n} / \mathrm{a}$ \\
\hline
\end{tabular}




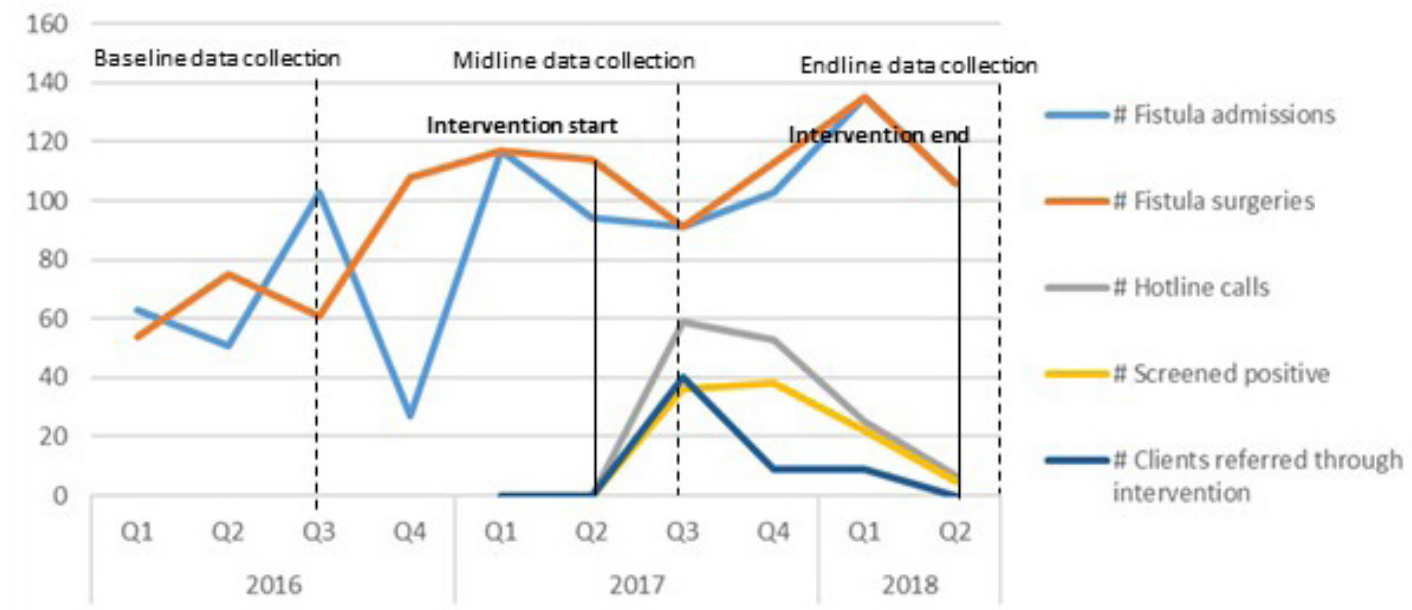

\section{FINDINGS}

\section{Facility Assessments}

PHC facility ownership remained constant from baseline to endline. With the exception of three privately owned facilities (10.5\%), all other PHC facilities are publicly owned (89\%). Most providers are community health extension workers offering 24-hour availability at nearly half of facilities (48\%). Overall, the functionality of basic facility commodities, including electricity, generators, running water, toilets, and supplies, remained constant from baseline to endline, though the number of power outages increased over time (from 51\% of facilities experiencing outages at baseline to $69 \%$ at endline).

The number of admissions and repair surgeries at fistlua centers, as documented in fistula center registers, increased during the intervention period (Figure 2). The hotline's reach beyond intervention communities suggests that the barrier reduction intervention may have played a role in improving access to fistula repair in Katsina. Program monitoring data show the increase, leveling and decrease in hotline callers, patients who were screened positive, and clients referred through any of the three communication channels, which follow the timeline and arc of intervention activities. Variation between numbers of admissions and surgeries completed could be due to factors unrelated to the intervention, such as challenges during pre-surgical preparation.

\section{FIGURE 3: FISTULA RECOGNITION \& CARE PRACTICES} OF PHC PROVIDERS (\%)

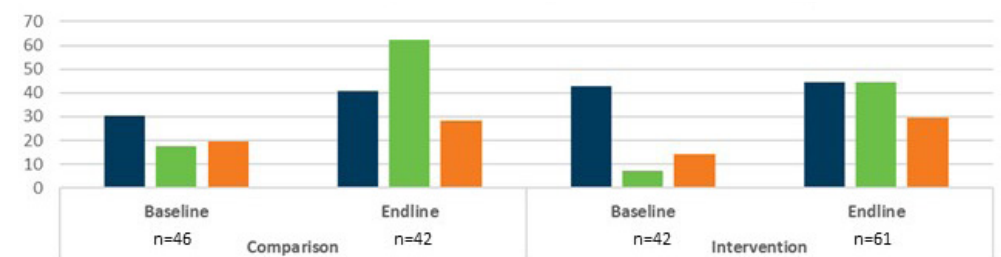

- Recognized obstructed or prolonged labor $\quad$ = Recognized women leaking urine $\quad$ Referred women with fistula symptoms

\section{PHC Providers}

Endline surveys took place with 42 and 61 providers in comparison and intervention communities, respectively. Findings were compared to baseline data from 46 and 42 comparison and intervention providers, respectively. PHC providers demonstrated moderate increases in recognition of fistula causes and symptoms following the intervention and subsequently made more referrals for fistula repair. More providers in intervention and comparison facilities recognized prolonged or obstructed labor at endline (44.3\% vs. $42.9 \%$, respectively) than at baseline (40.6\% and $30.4 \%$, respectively) (Figure 3).

Substantial increases in provider recognition of leaking urine as a symptom of fistula occurred in intervention $(7 \%$ to $44 \%$, baseline to endline) and comparison facilities ( $17 \%$ to $63 \%$, baseline to endline; $p<0.05)$. Referral for women with fistula symptoms also improved in intervention and comparison LGAs with more providers referring women at endline ( 30\%) compared to baseline ( 14-19\%). While practices are improving slowly in outpatient observation, providers' theoretical knowledge of urine and fecal

\section{TABLE 2: FISTULA REPAIR CLIENT SURVEY}

\begin{tabular}{|c|c|c|}
\hline Fistula experience indicator & $\begin{array}{l}\text { Baseline } \\
\mathrm{n}=81(\%)\end{array}$ & $\begin{array}{l}\text { Endline } \\
\mathrm{n}=44(\%)\end{array}$ \\
\hline $\begin{array}{l}\text { Clients who began leaking post- } \\
\text { delivery (obstetric fistula) }\end{array}$ & $80(98.8)$ & $42(97.7)$ \\
\hline $\begin{array}{l}\text { Fistula cases following normal } \\
\text { delivery* }\end{array}$ & $33(41.3)$ & $11(25.0)$ \\
\hline $\begin{array}{l}\text { Years clients lived with fistula (any } \\
\text { sort) }\end{array}$ & $\begin{array}{l}\text { Mean: } \\
1.78 \text { yrs; } \\
\text { Range: } \\
1-4\end{array}$ & $\begin{array}{l}\text { Mean: } \\
\text { 1.41 yrs; } \\
\text { Range: } \\
0-4\end{array}$ \\
\hline $\begin{array}{l}\text { Attempts to seek fistula treatment } \\
(\#)\end{array}$ & $\begin{array}{l}\text { Mean: } \\
2.3 x ; \\
\text { Range: } \\
1-4\end{array}$ & $\begin{array}{l}\text { Mean: } \\
\text { 5.1x; } \\
\text { Range: } \\
0-13\end{array}$ \\
\hline $\begin{array}{l}\text { Women who have previously sought } \\
\text { fistula treatment }\end{array}$ & 39 (48.1) & $19(43.2)$ \\
\hline
\end{tabular}




\begin{tabular}{|c|c|c|c|c|}
\hline \multirow[t]{2}{*}{ Barrier Index } & \multicolumn{2}{|c|}{ Baseline $(n=81)$} & \multicolumn{2}{|c|}{ Endline $(n=44)$} \\
\hline & 58 & 71.6 & 36 & 83.7 \\
\hline I did not know that fistula is a medical condition that can be treated. & 40 & 49.4 & 37 & 86 \\
\hline I did not know where to go for fistula repair. & 75 & 93.8 & 43 & 100 \\
\hline I was told by health providers (in the past) that my fistula will heal itself. & 74 & 92.5 & 42 & 97.7 \\
\hline I was told by health providers (in the past) that my fistula cannot be treated. & 29 & 35.8 & 32 & 74.4 \\
\hline I did not have money to pay for medical care to treat my fistula. & 44 & 54.3 & 12 & 27.9 \\
\hline The cost of transportation to repair sites and accommodation was too high. & 49 & 60.5 & 30 & 69.8 \\
\hline I fear traveling to the health facility because of pain/discomfort during travel. & 61 & 73.3 & 43 & 100 \\
\hline $\begin{array}{l}\text { I did not have someone to support me in seeking/reaching care at the fistula } \\
\text { center. }\end{array}$ & 39 & 48.1 & 7 & 16.3 \\
\hline I felt embarrassed because of my condition*. & 36 & 44.4 & 8 & 18.6 \\
\hline I felt isolated because of my condition*. & 62 & 76.5 & 36 & 83.7 \\
\hline I was afraid of harsh treatment by providers at the fistula $\mathrm{c}$ & 69 & 78.4 & 41 & 80.4 \\
\hline \multicolumn{5}{|l|}{ Additional Barriers } \\
\hline I felt ashamed of having obstetric fistula. & 15 & 18.5 & 4 & 9.1 \\
\hline I felt worthless. & 21 & 25.9 & 19 & 44.2 \\
\hline I felt am not as complete as a person because of fistula. & 26 & 35.5 & 3 & 7 \\
\hline I believed that my fistula was caused by diabolic means. & 74 & 91.4 & 40 & 93 \\
\hline Once others learnt of my condition, they did not allow me to work/earn money. & 30 & 37 & 14 & 33.3 \\
\hline I felt embarrassed about smell/leaking while travelling to facility. & 16 & 18.4 & 3 & 5.9 \\
\hline
\end{tabular}

leakage in the postnatal period remained low $(<8 \%)$ in intervention and comparison settings. This is likely due to focus on other pregnancy- and childbirth-related complications, such as bleeding and sepsis.

\section{Fistula Repair Clients}

Of the 81 women surveyed at baseline, 54\% were between 15-35 years of age, 86.4\% were married, and all were Muslim. Fifteen percent received formal education, $48 \%$ attended Quranic school, and 15\% ever worked for income. At endline, of 44 women surveyed, $46.5 \%$ were between 15-35 years of age, 90.2\% were married, 95.5\% were Muslim, and $2.3 \%$ were Christian. Thirty-two percent had formal education ( $26.7 \%$ completed primary only) and $12 \%$ had ever worked for income. The majority of women at baseline and endline came from rural areas within Katsina $(66.7 \%$ and $80.5 \%$, respectively). At baseline, $18.5 \%$ came to the fistula center from outside Katsina, while $>3 \%$ came from outside areas at endline.

The proportion of obstetric fistula cases remained constant from baseline to endline, though fewer cases were seen following normal delivery at endline than at baseline (Table 2). The reduction in the proportion of fistula cases following normal delivery at endline suggests that iatrogenic fistulas (caused during surgery, rather than vaginal birth) may be increasing in prevalence. Women seen at endline had been living with fistula less time, on average, than women at baseline. Though at endline, women had attempted to seek fistula repair care more than twice as many times compared to at baseline (5.1x compared to 2.3x).

\section{Barriers to Care}

Endline survey results (Table 3) show significant reductions in women's feelings of embarrassment and isolation in accessing fistula care $\left(p<0.05^{*}\right)$. Fewer women avoided fistula repairs due to inability to pay for medical care at endline ( $16.3 \%$ compared to $48.1 \%$ at baseline), but the proportion of women who believed fistula was caused by supernatural means remained constant at more than $90 \%$.

Awareness barriers persisted in Katsina after the intervention. More women interviewed at endline (83.7\%) reported not knowing fistula was a medical condition that could be treated, compared to $71.6 \%$ at baseline. Roughly equal numbers of women at endline and baseline were unaware of where to go for fistula repair. Knowledge gaps among PHC providers related to counseling persisted after the intervention as women continue to report being told that their fistula will heal itself or cannot be treated.

\section{INTERVENTION PROCESS, CHALLENGES, AND SUCCESSES}

Monitoring data from the FC+ intervention show 144 women called the fistula hotline for information about fistula and repair care options. One hundred and one women were screened positive and 88 received followup from a community volunteer. During the intervention 
period, 108 women were referred through the intervention (hotline, community agents, PHC providers) and 71 trips to and from the fistula center ccurred. Six of these referrals and trips came from the intervention LGA and were paid for using the transport voucher. Due in part to the hotline's reach, $90 \%$ of referred clients came from outside the intervention LGA.

Stakeholders consider the intervention, especially the hotline and transport, integral to eliminating barriers to fistula care access. Offering multiple, non-stigmatizing information channels and collaboration with transport agents promotes women's engagement in accessing repair care and prevents out-of-pocket spending.

\section{Training}

Intervention trainings were generally perceived as helpful in linking PHC providers and community volunteers, and in building their capacity to better prevent, identify, and refer for fistula. Providers in the intervention LGA demonstrated recall of training in birth preparedness, family planning, management of obstructed labor, and screening and referral through the job aid. PHC providers felt supported by a hands-on (refresher) training at the fistula center following midline feedback.

"I'm now aware of how to educate women and how to use the partograph in monitoring labor in the facility."

-PHC Provider, endline

Community volunteers felt better able to sensitize communities and refer women for repair care through the intervention processes and their general community mobilization activities. Community volunteers requested additional trainings to sustain their work.

"Before now I did not know that prolonged labor or surgery can cause this kind thing. I did not know about it. So I really learned more about these things."

-Community volunteer, endline

\section{Hotline}

Women, program managers, and others felt the hotline reduced stigma by providing confidentiality, particularly when the hotline was well-publicized and languagesensitive. The hotline's broad reach increased awareness, self- and community volunteer-guided referral, and transport to the fistula center.

"When you have the number, you will not even see the women... for instance, in a month you will not have [referred] anybody that has the problem, but they will be plenty in the hospital due to the hotline number. They will just go directly.

-Community volunteer, endline

Women and implementers cited challenges in using the mobile hotline, including women's lack of cell phone ownership and low literacy rates that inhibited response to the interactive voice response (IVR) language.
Communication challenges among PHC providers, NOFIC staff, and community volunteers may have impacted the intervention's effectiveness.

"Using the hotline is [difficult]; not everybody has a phone and not everybody knows how to operate a phone except by using the community volunteer"

-Community volunteer, endline

\section{Job Aids}

While some PHC providers reported not using the job aids, others found it useful in discussions with women about fistula.

"We really need to be using job aids because it helps to detect the women who have this problem and to know the possible solutions to it"

- Health provider, endline

Community volunteers had mixed feelings about the utility of their job aid - the hotline - in addition to network connectivity barriers. The hotline's poor reach to rural areas prevented community volunteers from maximizing its use and precluded their ability to encourage use of the transport voucher.

"We didn't get them [clients]; we are in urban areas. Some of the clients are in the villages. We are within the cities, and we didn't come with a single one, and that means we didn't use the hotline to refer any client." -Community volunteer, endline

\section{Transport Voucher}

The transport vouchers and reimbursements for transport were useful to NOFIC staff, transport agents, and women themselves. Challenges to voucher use were in part due to many women seeking repairs from outside the intervention area and unclear processes. Gendered concerns of women traveling alone in the communities created significant hesitance in accepting free transportation.

"It will not be easy for a community volunteer to go to
somebody's house to take his wife even if it [repair] is
free. We liaise with traditional rulers and leaders, and
they go there for pick up to have peace of mind."
-Program Manager, community-based org., endline While in intervention areas the transport voucher enabled free transport to the fistula center, in comparison areas women either paid for their own transport or, if screened by the hotline, received reimbursement.

\section{Health Systems Environment}

Institutionalizing the job aids and trainings, and sustaining linkages between stakeholders requires health systems support. Stakeholders perceived community volunteer engagement with the formal health system as integral in scaling up access to the NOFIC, given their proximity to and familiarity with communities where affected women live. Stakeholders emphasized the need for cross-sectoral 
collaboration and recognition of community volunteers by State Ministry of Health program officers.

"MCH department and health education promotion unit - we can come together, sit down, and see how we can really sustain this laudable project."

-Health program manager, endline

Stakeholders expressed concerns about the sustainability of each intervention component following $\mathrm{FC}+$ exit, asking whether women's access to PHC screening and repairs, enabled by community mobilization efforts, would continue. Concerns were raised about health worker turnover, limited PHC staff, and ambiguity about the NOFIC's ability to provide free repairs after financial support was withdrawn. Given the intervention's far reach beyond the intervention LGA, transport agents expressed concerns about the sustainability of their current role.

\begin{abstract}
"It's a matter of assistance. The project has ended now, and I have been called and I tell them [clients] the project has ended. Here in Katsina [LGA] I can immediately send a vehicle to pick them up, but if it is outside, I transport four to six from my pocket, and I advise them to come directly to the hospital."
\end{abstract}

-Community volunteer, endline

\section{CONCLUSIONS}

Reductions in psychosocial, financial, transportation, and some awareness barriers followed the implementation of the 3-1-1 intervention. While misconceptions of the causes of fistula decreased, knowledge gaps on fistula care options persist among women and communities. These are likely linked to prevailing awareness gaps at the PHC provider level. While the mass media, mobile hotline, and community volunteer intervention channels improved referral and access to the fistula center, including from outside intervention catchment areas, promotional materials and communications (the hotline in particular) need to be tailored to local languages. Communications publicizing the IVR need to be scaled up to rural communities in Northern Nigeria, where the majority of cases exist.

Small changes in PHC provider knowledge and practices suggest that, despite improvement, PHC provider awareness remains low. Further skill development requires refresher trainings and supportive supervision. To ensure social acceptability, scale up should emphasize the free transport-for-a-companion component of the intervention.

Though women still live with fistula for extended periods of time, the comprehensive and varied intervention approach, combined with adequate health systems support, emboldens women to seek repair services.
Study limitations reflect the challenge of measuring the effects of complex interventions in a real-world setting. The inability to isolate LGAs as purely intervention or comparison, due to the hotline coverage throughout Katsina State, limited researchers' ability to attribute observed changes to a component(s) of the intervention. A practical challenge was the lag between data collection and intervention timelines. Researchers did not interview women living with fistula before they sought care or before they received repair, and given the rarity of the condition at the population level, faced challenges recruiting postrepair women at endline. Data were cross-sectional; longitudinal PHC provider surveys would have allowed increased claims to causality, but were not feasible for pragmatic reasons, including turnover and selection for intervention trainings.

\section{KEY MESSAGES \& RECOMMENDATIONS}

- Complex interventions can be effective in reducing barriers to fistula treatment, but health systems and external stakeholders must ensure a supportive environment for sustainability.

- Coordination and communication between health systems and intervention actors to clarify roles and relationships can be achieved through refresher trainings.

- Trained PHC providers facilitated with adequate job aids can screen and refer fistula patients, thus improving access to treatment.

- Radio, hotline, and community agents were preferred sources of information for prevention and treatment information in communities.

- There is need for increased government support for referral and transport systems for fistula patients and their companions.

- With the expansion of IVR- based public health messaging, screening, and referral in low-resource settings, stakeholders should explore opportunities to integrate fistula - and other stigmatizing conditions - into existing platforms.

\section{CONTACT}

\section{Pooja Sripad}

Population Council, Washington D.C.

psripad@popcouncil.org

Emmanuel Nwala

Population Council, Abuja

enwala@popcouncil.org

Vandana Tripathi

EngenderHealth, Washington D.C.

vtripathi@engenderhealth.org

\section{REFERENCE}

1 ljaiya MA, Rahman AG, Aboyeji AP, Olatinwo AW, Esuga SA, Ogah OK, Raji HO, Adebara IO, Akintobi AO, Adeniran AS, Adewole AA. Vesico vaginal fistula: a review of Nigerian experience. West Afr J Med. 2010; 29(5):293- 8. 